\title{
CALDECOTT, KIPLING, ROSSETTI: TEXTOS INFANTIS VITORIANOS
}

\author{
CALDECOTT, KIPLING, ROSSETTI: VICTORIAN CHILDREN TEXTS
}

\author{
Guilherme Magri da Rocha ${ }^{1}$ \\ Sérgio Augusto Zanoto ${ }^{2}$
}

\section{Resumo}

Através de breves comentários sobre famosos textos de Randolph Caldecott, Rudyard Kipling e Christina Rossetti, pretendemos mostrar ao leitor de hoje como eram os textos infantis no período vitoriano, em que os autores herdaram o pensamento romântico e viam a criança e a infância como sendo puras, próximas à natureza de uma forma que o homem adulto não é. Textos moralizadores, eles visavam o aprendizado num mundo em que educar era tornar a criança um adulto.

Palavras-chave: Era Vitoriana. Literatura infantojuvenil. Literatura e história.

\begin{abstract}
Through brief comments on famous texts of Randolph Caldecott, Rudyard Kipling and Christina Rossetti, we intend to show to the reader aspects of children's literature written in the reign of Queen Victoria (1837-1901), in which authors inherited the Romantic idea that child and childhood are pure, close to nature in a way that the adult man is not. Moralizing texts, they taught children how to be an adult.
\end{abstract}

Keywords: Victorian Era. Children's literature. Literature and history.

\section{Considerações iniciais}

Vitória sucedeu seu tio Guilherme IV em um reinado que durou mais de sessenta anos (1837 - 1901) e simbolizou a época que se convencionou chamar de vitorianismo. Embora o mito tenha levado muito tempo para se formar, sobreviveu por muito tempo, até a Segunda Grande Guerra, quando a sociedade britânica passou por uma transformação radical. Para Jorge de Sena, o período é a “presunção definitiva” (p. 271) inglesa, que se formava desde Henrique VIII. Segundo o autor, a base intocável da sociedade vitoriana é a autoridade: “de ser-se inglês, de ser-se superior, de ser-se mais poderoso, ou mais rico - e da respectiva subordinação” (SENA, [19--], p. 272). Nesse período, muitas transformações aconteceram,

\footnotetext{
${ }^{1}$ Bolsista de Iniciação Científica financiado pela FAPESP. Departamento de Letras Modernas. Faculdade de Ciências e Letras de Assis. Universidade Estadual Paulista Júlio de Mesquita Filho. E-mail: magri.guilherme@hotmail.com

${ }^{2}$ Prof. Adjunto do Departamento de Letras Modernas. Faculdade de Ciências e Letras de Assis. Universidade Estadual Paulista Júlio de Mesquita Filho. E-mail: sazanoto@uol.com.br
} 
como a formação de uma numerosa e estável classe média, a estrutura industrial é transformada pela metalurgia, explorações minerais e a máquina a vapor, as descobertas científicas multiplicam-se, a geologia evolui, entre outros.

No âmbito literário, o público dessa nova classe média tentava se ajustar e alcançar o “desenvolvimento intelectual” proposto pelos românticos. Para Klingopulos (1958), é difícil dizer quanto território os escritores vitorianos ganharam (ou perderam); sua preocupação com a evolução e o intenso pessimismo/otimismo associado a ela agora parece datar e limitar essa produção intelectual, ao passo que muita poesia romântica mantém intacta a sua universalidade. Ainda segundo o autor, o período vitoriano e o romântico não devem ser separados, mas considerados uma única época. Essa dificuldade de separação cabe também aos textos infantis, que, como veremos adiante, absorvem muito das ideias românticas. O crescimento da produção dos textos infantis deve-se, por um lado, aos esforços dos vitorianos para que o trabalho infantil cessasse e, por outro, à introdução da educação obrigatória.

\section{A literatura infantil na Era Vitoriana}

Já disse Harold Bloom que os leitores que pretendem ler clássicos escritos por Chekhov, Henry James, Jane Austen ou mesmo Shakespeare estarão melhor preparados se antes tiverem passado pelos textos de autores como Edward Lear e Lewis Carroll, grandes representantes da literatura infantil, cujos escritos datam do século XIX. Bloom, sempre sagaz em suas afirmações, torna sua proposta bastante interessante ao propor obras que emancipam seu leitor. Carroll e Lear, considerados por muitos os pais do nonsense, escrevem numa época em que esse tipo de texto não pertencia a um gênero literário estabelecido.

A literatura destinada às crianças tem sua origem na tradição oral (mitos, fábulas, lendas, folclore, religião) e começam a surgir escritos, em inglês, no período medieval, sendo destinados apenas aos meninos e cujo objetivo era ensinar moral, boas maneiras e Latim. Orbis sensualium pictus ( $O$ mundo em imagens ${ }^{3}$ ), de Johann Amos Comenius, trata-se de uma gramática da língua latina, publicada em 1658 é considerada o primeiro livro infantil. Pilgrim’s process (A viagem do peregrino), 1678, de John Bunyan era o único texto, além da Bíblia, considerado adequado para leitura aos domingos. No século XVIII, Jean Jaques Rousseau discute que a criança naturalmente boa deve ser criada longe da sociedade, pois assim não seria corrompida por ela. O pensamento romântico de autores como William

\footnotetext{
${ }^{3}$ Todas as traduções foram feitas pelos autores do artigo.
} 
Wordsworth e William Blake ajudaram a criar a Era de Ouro da literatura infantil, no século XIX ao propor a criança como inocente e a infância como um período sagrado de vida (AVERY; HUNT; PAUL, VALLONE; ZIPES,2005).

Em An introduction to Children's Literature (Uma introdução à literatura infantil), Peter Hunt escreve que, no século XIX, a literatura para crianças estava crescendo (para longe dos adultos). No entanto, os textos ainda eram destinados, ou às meninas, ou aos meninos. Eles frequentavam a educação de baixíssimo custo do Monitorial System (Sistema Monitorial) inglês, enquanto elas ficavam com suas governantas, geralmente meninas com certa educação, de famílias arruinadas. Vejamos dois exemplos de duas resenhas de textos da época:

\begin{abstract}
With the Sea Kings. A Story of the Days of Lord Nelson. By F.H. Winder. With 6 page Illustrations by W.S. Stacey. Crown 8vo, \$1.50. - "Just the book to put into a boy's hands. Every chapter contains boardings, cuttings out, fighting pirates, escapes of thrilling audacity, and captures by corsairs, sufficient to turn the quietest boy's head. The story culminates in a vigorous account of the battle of Trafalgar, as seen from the Victory. Happy Boys!" \&mdash The Academy. ("Com os reis do mar, os dias de Lorde Nelson, por F.H. Winder, com seis páginas ilustradas por W.S. Stacey. $13 \times 19 \mathrm{~cm}$, \$1.50. 'O livro certo para ser colocado nas mãos de um menino. Todos os capítulos contém abordagens, cortes, combates com piratas, fugas audaciosas e capturas por corsários, o suficiente para agitar o mais quieto dos meninos. A história culmina num vigoroso relato da batalha de Trafalgar, como visto do Victory. Meninos felizes!'”)

Banshee Castle. By Rosa Mulholland. With 12 page Illustrations by John H. Bacon. Crown 8vo, olivine edges, $\$ 1.50$ - "One of the most fascinating of Miss Rosa Mulholland's many fascinating stories. . The charm of the tale lies in the telling of it. The three heroines are admirably drawn characters." \&mdashAthenaeum. (LAM, 2007, sem página) ("Castelo Banshee, de Rosa Mulholland, com 12 páginas ilustradas por John H. Bacon. $13 \times 19 \mathrm{~cm}$, bordas de olivina, \$1.50. 'Uma das mais fascinantes de todas as histórias fascinantes da senhorita Rosa Mulholland... O charme da história está em contá-la. Três heroínas são personagens admiráveis’”)
\end{abstract}

Esses textos fazem parte de um catálogo chamado Popular books for Young children (Textos populares para crianças), publicado em 1894 por Charles Scribnere. Enquanto a primeira resenha, para meninos, tem certos detalhes, um tom mais ativo e que acaba por revelar, de certa forma, o enredo, a segunda, para meninas, não provoca curiosidade alguma, parece mais um aviso vago. Embora a literatura para crianças, até então, não tivesse essa separação entre gêneros, a demanda por textos para crianças cresceu tanto que os autores e os editores resolveram que, dessa forma, isto é, fazendo essa distinção, aumentariam o interesse pelos livros e facilitariam o acesso aos textos (LAM, 2007). Os pais os pequenos buscavam por textos que, em vez de valorizar a diversão, preparavam as crianças para seguir uma religião, aceitar e receber os valores sociais e culturais da época. 


\section{Randolph Caldecott}

Embora a impressão em cores seja praticada desde 1840, é na Era de Ouro que ilustradores, individualmente, ganham destaque e Caldecott (1846-86) é, para Peter Hunt, um dos grandes da época. Aos vinte e seis anos, mudou-se da cidade sede do condado de Cheshire para Londres, trabalhando em período integral como ilustrador de livros e periódicos, o que lhe permitiu tornar-se amigo de diversos artistas da época, como Dante Gabriel Rossetti e John Everett Millais. Com Walter Crane e Kate Greenaway, era um dos mais prestigiados ilustradores do final da Era Vitoriana. Pensemos nas ilustrações que ele fez para "Bye, baby bunting” (“Tchau, bebê enrolado”), que pode ser encontradas no livro HeyDiddle-Diddle, and Baby Hunting (1882) ${ }^{4}$.

Embora haja uma data que ateste a primeira vez que fora recolhida em livro, "Bye, baby bunting” é uma canção de ninar inglesa bastante popular e, como muitas outras, tem sua origem na tradição oral, o que faz com que ela não possamos creditá-la a nenhum autor. O pequeno texto é composto, em sua versão mais conhecida, por quatro versos, "Bye, baby bunting, / Daddy’s gone a-hunting, / Gone to get a rabbit skin / To wrap the baby bunting in.” (“Tchau, bebê enrolado, / Papai foi caçar / Pegar pele de coelho / Pra enrolar o bebê”) e foi escolhido para iniciar este artigo por um motivo claro, sua sobrevivência ao tempo e sua fama: os amantes de séries de televisão devem ter reconhecido a interpretação da canção no episódio que encerrou a primeira parte da terceira temporada de “The Walking Dead”, uma das mais famosas séries da American Movie Classics (AMC). Canções de ninar como "Bye, baby bunting” estão entre os primeiros contatos dos recém-nascidos com a música e são consideradas uma das formas mais antigas de verso.

As ilustrações de Caldecott (texto lato sensu) nos assemelham à ideia de criança que percebemos em “Immortality ode” (1807) de William Wordsworth (1770-1850). No poema, o autor inglês discute, de certa forma, a ideia de Natureza que encontramos em Rousseau (1712-1778): o eu-lírico relembra a pureza da infância, sua proximidade com a natureza, quando ainda não havia sido corrompido pela sociedade e seus costumes, era mais próximo da origem. Ele nos mostra que a aproximação da natureza também é aproximação do divino, sendo as crianças, portanto, mais próximas de Deus, "trailing clouds of glory do we come / From God who is our home," ("Viemos de nuvens de glória / De Deus, que é nossa casa”),

\footnotetext{
${ }^{4} \mathrm{O}$ link para as obras completas, que contém os textos estudados, podem ser encontrados junto à bibliografia.
} 
"Shades of the prison-house begin to close / Upon the growing boy" (Sombras da prisão começam a se fechar / Diante do garoto que cresce”). Semelhanças com os ideais românticos também podem ser vistos nas ilustrações de Walter Crane (1945-1915).

A natureza, como representada nas ilustrações que Caldecott faz dos textos, é platonizada; "revelation and self-knowledge become possible: nature is a projection of na ideal condition, a Garden of Eden, hence a reflection of the purity and grace of the Romantic child” (JOSEPH, 2006, p.11) ("a revelação e o autoconhecimento tornam-se possíveis: a natureza é uma projeção da condição ideal, o Jardim do Éden, que reflete a pureza e graça da criança romântica”) e tal perspectiva não restringe-se, claro, à ilustrações.

\section{Rudyard Kipling}

Mais conhecido pelo texto The jungle book (O livro da floresta), de 1894, que resultou no famoso filme da Disney, Kipling (1865-1936) publicou, em $1902^{5}$ o livro Just so stories. Muitos dos clássicos infantis surgiram nesse ano, como Songs of childhood, de Walter de la Mare e The Tale of Peter Rabbit de Beatrix Potter.

Em "How the camel got his hump" (Como nasceu a corcova no camelo), do inglês Rudyard Kipling (1865-1936), publicado em 1902 em Just so stories, o narrador nos explica, como o próprio nome sugere, o porquê o camelo, diferentes dos outros animais, possui uma corcova. O animal, quando o mundo acabara de nascer, era um preguiçoso, que vivia no deserto e só sabia blaterar e comer gravetos e tamargueiras; mas ao contrário da árvore presente nos versículos de Jeremias, o camelo não confrontava nenhuma adversidade, não fazia nada que não lhe agradasse, enquanto três outros animais, personagens secundários, o cavalo, o cachorro e o boi, ao longo da fábula, sugeriram trabalho ao companheiro, que sempre recusava. O autoconhecimento e a revelação aparecem para o camelo através da

\footnotetext{
${ }^{5}$ Entendemos que, em 1902, o período referente ao reinado da Rainha Vitória já havia se encerrado; contudo, é importante compreendermos que a literatura não tem, como período, técnica e estilo, uma data que representa, prontamente, seu fim. O texto de Kipling compõe, num campo maior, o período entendido pelos estudiosos como Era de Ouro da literatura infantil, que se iniciou com o "nonsense” de Edward Lear (1812-1888), autor de The book of nonsense, de 1846 e Lewis Carroll (1832-1898), pseudônimo de Carles Lutwidge Dodgson, autor de Alice's adventures in Wonderland, de 1865 e cujo término é considerado o começo da Primeira Guerra Mundial (1914).
} 
punição: sua preguiça, no final do texto, é o que faz com que cresça nele uma corcova, e ele passa a conseguir ficar mais tempo sem se alimentar, para trabalhar mais. A criança aprende que a submissão (do camelo ao gênio, que é seu dono), além de ser algo natural, também é uma coisa boa, mantém uma hierarquia social necessária.

\section{Christina Rossetti}

Rossetti (1830-1894) começou a escrever com onze anos de idade. Seus primeiros versos publicados por seu avô paterno, Gaetano Polidorim, em 1847. Ela escrevia para o "The Germ” (“O Germe”), periódico que teve somente quatro edições (1850), editado por William Rossetti, cujo principal objetivo era, como o próprio título propõe, divulgar/germinar as ideias dos Pré-Rafaelistas, em que assinou sob o pseudônimo Ellen Alleyn. Sua poesia, para o professor regius emeritus da Universidade de Edimburgo, Alastair Fowler, "possui uma delicadeza de sentimentos muito mais pura que a de seu irmão” (FOWLER, 1987, p.340). “A voz da poetiza é autêntica, sinceramente natural ao ponto da profunda intimidade confessional, quando partilha o monótono pathos da depressão" (idem). Os poemas de Christina não são tão artificialmente sofisticados quanto os de Dante Gabriel, embora também sugiram a forma e o design do movimento Pré-Rafaelista, bem como suas cores e vocabulário. A tristeza e a frequente morbidez são recorrentes, não só nos poemas religiosos, como também em seus textos infantis.

A figura da mãe, nos textos infanto-juvenis vitorianos, é idealizada; aproxima-se do divino ao representar aquela que seria um anjo, a guardiã, pois toma conta não só das crianças, mas também do lar em si; é um modelo para aquelas que, um dia, serão mulheres casadas, mães de família, anjos que guardam seu próprio lar. No livro de poemas Sing-song: a nursery rhyme book ("Livro de canções para crianças”), obra de Christina Rossetti (18301894) publicada em 1872, muitos dos textos fazem com que o leitor compreenda a importância da mãe em casa. Vejamos o poema a seguir, chamado “A motherless soft lambkin” (“Um cordeirinho sem mãe”), parte do livro:

A motherless soft lambkin / Alone upon a hill; / No mother's fleece to shelter him / And wrap him from the cold: - / I'll run to him and fetch him, that I will; / I'll care for him and feed him / Until he’s Strong and bold ("Um cordeirinho sem mãe / Sozinho na colina / Sem a lã de sua mãe para agasalhá-lo / E protegê-lo do frio -/ Eu 
correrei até ele e o buscarei, isso farei / Tomarei conta dele e o alimentarei / Até que fique forte e vigoroso”) (ROSSETTI, 2006, p.1171)

Uma primeira leitura do belíssimo poema, em sentido literal, nos permitirá encontrar, no texto, uma preocupação com os animais: devemos ser gentis com eles; tema pelo qual as mulheres da classe média vitoriana discutiam ativamente. Contudo, como o leitor já deve ter percebido, o texto se trata da importância materna na vida da criança: o pequeno cordeiro só encontra-se desabrigado porque não está presente em sua vida aquela que o ampararia, ele perdeu a companhia de sua mais bondosa aliada e isso é insuperável. A colina, a neve e a expressão do cordeirinho presentes na ilustração do pré-rafaelista Arthur Hughes (18321915), que não é apenas um desenho, não está ali por acaso, nos faz refletir, pensarmos em como nosso lar é um lugar necessário, seguro e aconchegante, ao contrário do desconhecido, daquilo que está fora de casa, longe dos pais; o cordeiro é o órfão, figura presente em abundância nos textos moralizantes vitorianos, crianças que eram associadas aos ciganos e aos estrangeiros, acusadas de não serem inglesas legítimas, mas uma mistura de raças (BANERJEE, 2007, sem página). Em outra leitura, é interessante observarmos que a figura feminina que Hughes integra ao texto salva o cordeiro que representa, metaforicamente, o Salvador.

\section{Conclusão}

Todos os textos estudados permitem a criação de novos mundos, a capacidade de visualizar o que nós, inicialmente, não enxergamos e, ao ampliar, ainda que de maneira direcionada, moldada, a visão de mundo daquele que os lê, são capazes de atribuir e auxiliar a construção de novos conhecimentos. Nós não somos seres acabados, não temos uma fórmula que determine como vamos reconhecer certa mensagem; somos únicos e, dentro de nossa imaginação, também única, tudo pode acontecer: ela que nos permite refletir sobre textos maravilhosos, como os de Kipling.

No entanto, a interação entre o texto do autor e a fruição deste pelo leitor, nas obras em questão, dado o seu aspecto moralizador, instrutivo, realiza-se parcialmente. Isto é, não é permitido ao leitor outra apreciação, que não aquela intencionada com um fim específico: educar, evangelizar, entre outros aspectos. Para os mais jovens, um terceiro polo, o leitor/intérprete do texto - o tutor ou professor para os adolescentes que são capazes de ler e 
entender o texto - desempenha tal papel não mais lendo o texto, mas checando a leitura desse texto, isto é, se os princípios morais estabelecidos ou ensinados pelos textos foram devidamente compreendidos.

Lewis Carroll, contemporâneo dos autores citados, com suas Alices, subverte todo esse princípio didático-moralizante estabelecido, mesmo que a interação continue a ter um terceiro polo leitor/intérprete, ao propor uma leitura pelo prazer da leitura, sem princípios morais, religiosos, bem ou mal, apenas uma viagem por outro mundo, dando início a um novo modo de enxergar a criança e os textos direcionados a elas.

\section{Referências}

AVERY, G. ... [et al.] The norton antology of children's literature: the traditions in English. New York, London: Norton, 2005.

BANERJEE, J. Ideas of childhood in Victorian Children's Fiction: the child as innocent. Disponível em: <<http://www.victorianweb.org/genre/childlit/childhood1.html $>>$. Acesso em 01 fev. 2013.

BLOOM, H. Stories and poems for extremely intelligent children of all ages. New York: Touchstone Book, 2002.

CALDECOTT, R. Diddle diddle and baby bunting. Disponível em: <http://www.gutenberg.org/files/19177/19177-h/19177-h.htm>. Acesso em 01 fev 2013.

FOWLER, A. História da literatura inglesa: formas e gêneros desde a Idade Média à actualidade. [S.l] : Publicações Europa-América, 1987.

HUNT, P. An introduction to Children's literature. New York: Oxford University, 1994.

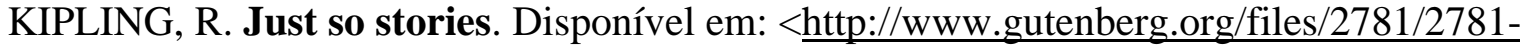
h/2781-h.htm>. Acesso em 01 fev. 2013.

KLINGOPULOS, G. D. The literary scene. In: FORD, B. The Pelican guide to English Literature: from Dickens to Hardy. Baltimore: Penguin, 1958.

LAM, S. Boys will be Boys, and Girls should be Girls: genre in Children’s Literature. Disponível em: <http://www.victorianweb.org/genre/childlit/boysandgirls.html>. Acesso em 01 fev 2013. 
PEREZ, S. M. R. Little lambs, linnets and babes in the snow: messages of kindness and caution in Christina Rossetti’s Sing song and Speaking likenesses. 2011. 46 p. Dissertação (Mestrado) - Iowa State University. Ames, Iowa, 2011.

ROSSETTI, C. Sing-song: a nursery rhyme book. Disponível em:

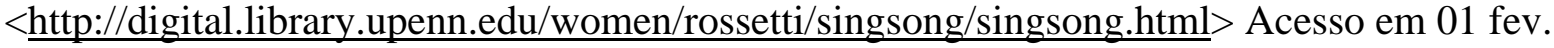
2013.

SENA, J. A literatura inglêsa : ensaio de interpretação e de história. São Paulo : Cultrix, [19--]

SETON, E. T. Wild animals I have known. Disponível em:

<http://www.gutenberg.org/files/3031/3031-h/3031-h.htm> Acesso em 10 fev. 2013. 